\title{
HIGH RESOLUTION COMPUTED TOMOGRAPHY AND CHEST RADIOGRAPHY FINDINGS AMONG INTERSTITIAL LUNG DISEASE PATIENTS
}

Anusmriti Pal ${ }^{1,}$, Manoj Kumar Yadav ${ }^{1}$, Chiranjibi Pant ${ }^{1}$, Bishow Kumar Shrestha ${ }^{1}$

${ }^{1}$ Department of Pulmonary, Critical Care and Sleep Medicine, Chitwan Medical College, Bharatpur-10, Nepal.

\author{
Received: 23 Nov, 2019 \\ Accepted: $10 \mathrm{Dec}, 2019$ \\ Published: 27 Dec, 2019 \\ Key words: High resolution computed tomogra- \\ phy; Idiopathic pulmonary fibrosis; Interstitial lung \\ disease. \\ *Correspondence to: Anusmriti Pal, Department of \\ Pulmonary, Critical Care and Sleep Medicine, Chitwan \\ Medical College, Bharatpur-10, Nepal. \\ Email: anusmritipal@gmail.com \\ DOI:https://doi.org/10.3126/jcmc.v9i4.26895 \\ Citation \\ Pal A, Yadav MK, Pant C, Shrestha BK. High resolu- \\ tion computed tomography and chest radiogra- \\ phy findings among interstitial lung disease pa- \\ tients.2019;9(30):24-27.

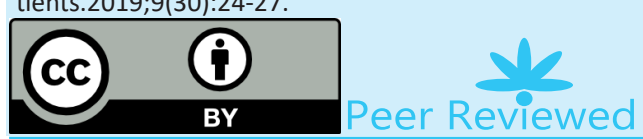

\section{INTRODUCTION}

Interstitial lung disease (ILD) is a heterogeneous group of diffuse parenchymal lung diseases (DPLD), characterized by restrictive physiology, impaired gas exchange, pulmonary inflammation and fibrosis. In most cases the pathology of ILD lies in the pulmonary interstitium which consist of connective tissue space between the alveolar epithelial cells and the adjacent capillary endothelial cells. ${ }^{1}$ ILD predominantly affects lung parenchyma characterized by alveolar, septal thickening, fibroblast proliferation, and pulmonary fibrosis. Although it primarily affects adults, few seen in young age e.g. Sarcoidosis, Pulmonary Langerhans's cell histiocytosis whereas idiopathic pulmonary fibrosis (IPF) usually presents between 40 to 70 years of age. ${ }^{2}$ Diagnosis requires workup of clinical presentation, lifestyle, occupational history, exposures, and drug history forming the clinical context. ${ }^{3}$

The chest radiograph remains part of the initial assessment of ILD, but the patterns are often nonspecific and insensitive to early ILD. It has limited accuracy due to superimposition of structures and poor contrast resolution. ${ }^{3}$ High Resolution Computed Tomography (HRCT) has higher sensitivity than CXR, is indicated among ILD suspicion patients. However, it has few limitations; $10-20 \%$ of patients can have a normal HRCT. ${ }^{4}$

The objective of the study was to study the findings of conventional CXR and HRCT chest among ILD patients, radiological patterns and disease distribution.

\section{METHODS}

An observational, descriptive, cross-sectional, single centred study was conducted at Chitwan Medical College Teaching Hospital (CMCTH) over the period of 6 months starting from January 2019. Approval was taken from Institutional Review Committee of CMCTH (Ref: CMC-IRC/076/077-007 on January 02, 2019). Informed consent was taken after explaining about the study.

All the patients who presented in our department with the diagnosis of ILD having CXR and HRCT chest, either inpatient or outpatient were enrolled in the study. Pregnant patients or those unwilling to participate were excluded.

HRCT chest scan was carried out in 64 slice CT machine using $120 \mathrm{kV}$, 200mA with scan time per slice as 1-2 sec with 
slice thickness 1-2 mm. All HRCT chests were interpreted by pulmonologist.

Data were collected using a structured proforma covering the relevant details. Then the data were filled in SPSS 16 . Students t-test for comparison of means and chi-square test for comparison of proportions (percentage) was used and results were analysed.

\section{RESULTS}

A total of 30 patients were enrolled, the mean age was 56.00 \pm 16.51 years (Range: 25 - 79 years). Out of which 17 were (56.7\%) female and $33.3 \%$ of the patients were smokers, with median smoking pack years being 22.5. The median duration of illness was 5 months (Range: 0.5 - 48 months). A vast majority (90.0\%) of them presented with multiple complaints ( $\geq 2$ complaints), the predominant complaints being dyspnoea (73.7 \%) and cough (83.3\%).

Most common pattern associated with ILD was reticular opacity, which was observed in $50 \%$ on CXR and $56.6 \%$ on HRCT chest. The number of findings in HRCT chest for a patient was significantly higher than CXR findings (Median number: 4 vs. $2, \mathrm{p}<0.001$ ) (Table 1).

Table 1: Patterns found in suspected cases of ILD on HRCT chest with chest radiograph correlation.

\begin{tabular}{|l|l|l|l|}
\hline $\begin{array}{l}\text { S. } \\
\text { No. }\end{array}$ & Radiological findings & CXR & HRCT \\
\hline 1 & Normal & N (\%) \\
\hline 2 & Reticular opacities & $1(3.3)$ & $0(0.0)$ \\
\hline 3 & Airspace opacities & $15(50.0)$ & $17(56.6)$ \\
\hline 4 & Traction bronchiectasis & $1(3.3)$ & \\
\hline 5 & Bronchiectasis & $1(3.3)$ & $13(43.3)$ \\
\hline 6 & Ground glass haze & $1(3.3)$ & $5(16.7)$ \\
\hline 7 & Fibrosis & $11(36.7)$ & $15(50.0)$ \\
\hline 8 & Honeycombing & $4(13.3)$ & $8(26.7)$ \\
\hline 9 & Nodules & $2(6.7)$ & $10(33.3)$ \\
\hline 10 & Consolidation & $5(16.7)$ & $7(23.3)$ \\
\hline 11 & Lung cyst & $4(13.3)$ & $5(16.7)$ \\
\hline 12 & Decreased lung volumes & $3(10.0)$ & $2(6.7)$ \\
\hline 13 & Pleural effusion & $1(3.3)$ & $4(13.3)$ \\
\hline 14 & Septal thickening & & $14(46.7)$ \\
\hline 15 & Lymphadenopathy & $3(10.0)$ & $13(43.3)$ \\
\hline 16 & Dilated pulmonary artery & & $3(10.0)$ \\
\hline 17 & Others & & $3(10.0)$ \\
\hline & & & $1(3.3)$ \\
\hline
\end{tabular}

Distribution of diseases as diagnosed by HRCT chest, most common was DPLD of known cause (53.3\%) among which connective tissue disease related ILD were frequent $(26.7 \%)$ (Table 2).
Table 2: Distribution of underlying diseases by HRCT chest findings

\begin{tabular}{|l|l|}
\hline DPLD classification & Frequency (\%) \\
\hline DPLD of known cause & $16(53.3 \%)$ \\
\hline Drug induced PF & $1(3.3 \%)$ \\
\hline Hypersensitivity pneumonitis & $4(13.3 \%)$ \\
\hline CTD-ILD* & $8(26.7 \%)$ \\
\hline Silicosis & $1(3.3 \%)$ \\
\hline Disseminated TB & $1(3.3 \%)$ \\
\hline IBD-associated & $1(3.3 \%)$ \\
\hline Idiopathic Interstitial Pneumonia & $10(33.3 \%)$ \\
\hline IPF & $7(23.3 \%)$ \\
\hline Smoking related PF & $1(3.3 \%)$ \\
\hline AIP & $1(3.3 \%)$ \\
\hline NSIP & $1(3.3 \%)$ \\
\hline Granulomatous DPLD & $4(13.3 \%)$ \\
\hline Sarcoidosis & $4(13.3 \%)$ \\
\hline
\end{tabular}

*4 cases were Rheumatoid Arthritis (RA) associated, 3 were scleroderma associated

The diagnosis of DPLD according to the pattern present in CXR and HRCT chest are shown in the Figure 1 and 2 respectively. Reticular pattern is mostly seen in CXR whereas Usual Interstitial Pneumonia (UIP) pattern is common in HRCT chest.

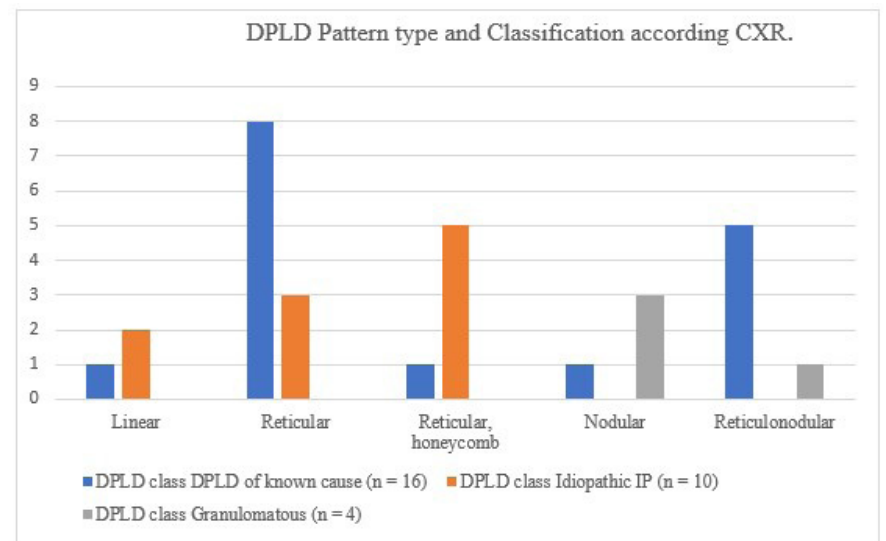

Figure 1: DPLD Pattern type and Classification according CXR DPLD Pattern type and Classification according HRCT

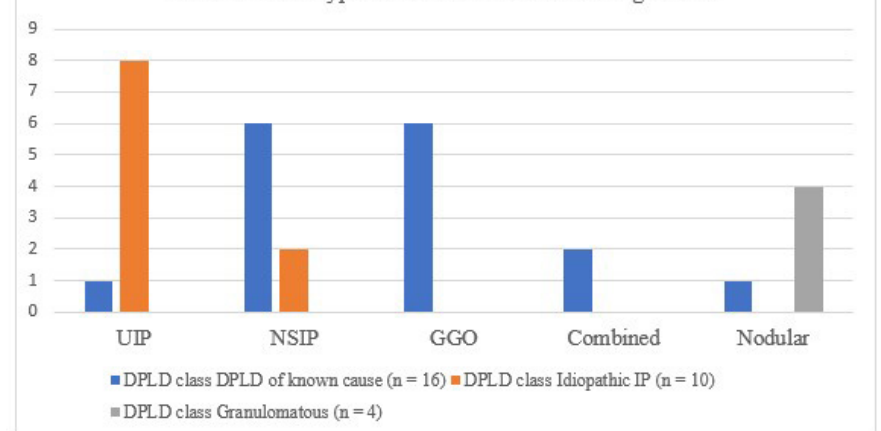

Figure 2: ED LOS in hours among patients Admitted to Critical Areas 


\section{DISCUSSION}

A total 30 patients with ILD who presented to our department over a period of six months were included. Predominantly were females $56.7 \%$ of mean age being $56.00 \pm 16.51$ years (Range: 25-79 years). Similar kind of results were seen in S. Annapurna et al study (Age $60-80$ years; $F>M$ ); Bhat et al (Age $22-85$ years $\left(\right.$ mean $=53.5$ years), $56 \% \mathrm{~F}$ ) ${ }^{2,5}$ In contrast Siddhant S. Lolge et al study (60\% M, age 24-74 years) and Agrawal MK et al study (40 patients $65 \% \mathrm{M}$, age $30-74$ years) showed male predominance. ${ }^{6,7}$

Another similarity with S. Annapurna et al was higher numbers of findings detected by HRCT chest as compared to chest radiographs HRCT chest can detect disease processes much earlier in their evolution and could characterize the abnormality location much more accurately. ${ }^{5}$ HRCT chest scans are essential to the diagnostic work-up since each ILD form is characterized by a specific pattern of abnormalities and a confident diagnosis can often be arrived by HRCT chest alone or in correlation with the clinical symptoms. ${ }^{5}$

Most common findings were reticular opacities (56.6\%) detected in HRCT chest compared to CXR but the difference between these two methods were not significant. Other common findings detected frequently in HRCT chest were traction bronchiectasis (43.3\%), honey combing (33.3\%), septal thickening $(46.7 \%)$, ground glass opacity (GGO) $(50.0 \%)$, nodules (23.3\%). Similar findings were observed by C. K Onyambu et al, where predominant reticular opacities (56.1\%), honeycombing (37.8\%), GGO (26.8\%) pattern on HRCT chest among ILD patients. ${ }^{8} \mathrm{~S}$. Annapurna et al study revealed septal thickening $(n=37 ; 64 \%)$ followed by bronchiectasis $(n=26 ; 52 \%)$ and GGO ( $n=24 ; 48 \%)$ in HRCT chest. $^{5}$

In C. K Onyambu et al study $30.7 \%$ of patients had a normal CXR.8 Where as we observed only 1 (3.3\%) had normal CXR. Palve et al observed CXR completely normal in 2/30 (6.6\%). Therein lies the inherent lack of sensitivity of conventional chest radiography in the diagnosis of these conditions. ${ }^{3}$

The most common findings in CXR during our study were reticular opacities (50\%), GGO (36.7\%), nodules (16.7\%). Similarly, S. Annapurna et al noted various patterns on CXR were reticular opacities $(n=21 ; 42 \%)$, increased opacity $(n=10$; $20 \%$ ) and nodular opacities $(n=6 ; 12 \%) .{ }^{5}$ In Siddhant S. Lolge et al study CXR findings were reticular opacities $(n=21 ; 70 \%)$,

\section{REFERENCES:}

1. Patil PB, Kawade D, Titare Prashant, Kaginalkar VR. HRCT Assessment of Interstitial Lung Diseases. International Journal of Contemporary Medical Research. 2016;3(8). [DOI]

2. Bhat IM, Bhat JA, Shamshad M, Malik AA, Mir S. Role of High-resolution Computed Tomography Chest in Interstitial Lung Diseases. International Journal of Scientific Study. 2016;4(2). [DOI]

3. Palve DR, Verma DP, Chandnani DS. Comparison between chest radiograph and hrct chest in cases of interstitial lung disease. Paripex - Indian journal of research. 2016; 5(12). [DOI]

4. Elicker B, Pereira CAC, Webb R, Leslie KO. High-resolution computed nodular opacity $(n=9 ; 30 \%)$, GGO $(30 \%){ }^{6}$

The spectrum of diseases diagnosed were Idiopathic Pulmonary Fibrosis (IPF) ( $n=8 ; 26.7 \%)$, Connective tissue disease related ILD (CTD-ILD) (26.7\%), Hypersensitivity Pneumonitis (HP) (13.3\%) and Sarcoidosis (13.3\%) most commonly. Among CTDILD most common was Rheumatoid Arthritis (RA) (4/8) and scleroderma (3/8). Siddhant S. Lolge et al observed Sarcoidosis (23.3\%), RA (10\%), IPF (23.3\%), HP (6.7\%). ${ }^{6}$ Bhat et al study revealed common presentation in HRCT chest as IPF (32\%), RA (26\%), followed by scleroderma (20\%) cases. $^{2}$

The spectrum of diseases included in Agrawal MK et al study was IPF (25\%), HP (17.5\%), Sarcoidosis (15\%), RA (10\%), Silicosis (10\%) and others. ${ }^{7}$ In Meraj Rentia et al study spectrum of diseases was IPF (25\%), idiopathic NSIP (16.5\%), RA (14.5\%), lymphangitis carcinomatosis (8.33\%), asbestosis (6.25\%), HP $(6.25 \%)$ were common out of which 2 of 48 patients (4.16\%) had normal CXR. ${ }^{9}$

Florence Jeny et al study reveals that CXR has been helpful in detecting ILDs, due low irradiation dose and availability it appears normal in $10-40 \%$ of patient's, diagnostic yield was achieved in $23 \%$ for radiography versus $49 \%$ for HRCT in ILDs. ${ }^{10}$

This study was limited by small sample size, single-centre design also HRCT findings less diagnosed and cross checked by the radiologist in the $\mathrm{CT}$ scanner console.

\section{CONCLUSION}

The present study concluded CXR being the modality for preliminary diagnosis and screening of patients is relatively insensitive modality for the diagnosis. HRCT chest proved to be an ultimate modality for near to accurate diagnosis of the pathology. It may even obviate the need for a lung biopsy. HRCT was found superior to CXR in detection of all basic patterns and their distribution. Chest radiograph is nonspecific initial investigation to diagnose ILD. HRCT could demonstrate the different patterns of disease and their distribution in lungs.

\section{CONFLICT OF INTEREST}

None

\section{FINANCIAL DISCLOSURE}

\section{None}

tomography patterns of diffuse interstitial lung disease with clinical and pathological correlation. J Bras Pneumol. 2008; 34(9):715-44. [DOI]

5. Annapurna S, Badarke P, Chandra E. Study of Interstitial Lung Disease with reference to radiological profile. Asian Journal of Medical Radiological Research. 2018; 6(1):15-21. ISSN (P): 2347-3371. [DOI]

6. Lolge SS, Kachewar SG, Ghule SS, Lakhkar DL, Tamhane TM, Shinde PP. Comparative study of HRCT thorax with plain chest radiograph in evaluating the patients with interstitial lung diseases. Scholars Journal of Applied Medical Sciences. 2016;4(11C):4028-33. ISSN 2320-6691 (Online). [DOI]

7. Agrawal MK, Kumar A, Agrawal R, Rana R. To study the significance of HRCT over Chest x-ray in the diagnosis of interstitial lung diseases. J.Evolution Med.Dent.Sci. 2019; 8(02):94-98. [DOI] 
8. Onyambu CK, Waigwa MN. Pattern of interstitial lung disease as seen by high resolution computerised tomography. East African Medical Journal. 2012; 89(9):285-93. [DOI]

9. Rentia $M$, Singla $H$, Malpani $D$, Vaishnav $T$, Jhala $P$. Radiological analysis of interstitial lung diseases. IAIM, 2015; 2(6): 69-76. [LINK]
10. Jeny F, Brillet PY, Kim YW, Freynet O, Nunes H, Valeyre D. The place of high-resolution computed tomography imaging in the investigation of interstitial lung disease. Expert review of respiratory medicine. 2019 Jan 2;13(1):79-94. [DOI] 